\title{
In the absence of apoptosis, myeloid cells arrest when deprived of growth factor, but remain viable by consuming extracellular glucose
}

\author{
Li Dong ${ }^{1} \cdot$ Boris Reljic ${ }^{1} \cdot$ Jen G. Cheung ${ }^{1}$ Elizabeth S. $\mathrm{Ng}^{2} \cdot$ Lisa M. Lindqvist ${ }^{1}{ }^{1}$ Andrew G. Elefanty ${ }^{2,3}$ • \\ David L. Vaux $\mathbb{B}^{1} \cdot$ Hoanh Tran $\mathbb{B}^{1}$
}

Received: 12 June 2018 / Revised: 17 December 2018 / Accepted: 20 December 2018 / Published online: 15 February 2019

(c) ADMC Associazione Differenziamento e Morte Cellulare 2019

\begin{abstract}
Withdrawal of the growth factor interleukin-3 (IL-3) from IL-3-dependent myeloid cells causes them to undergo Bax/Bak1dependent apoptosis, whereas factor-deprived $\mathrm{Bax}^{-1-} \mathrm{Bakl}^{-1-}$ cells remain viable, but arrest and shrink. It was reported that withdrawal of IL-3 from $\mathrm{Bax}^{-1-} \mathrm{Bakl}^{-1-}$ cells caused decreased expression of the glucose transporter Glut1, leading to reduced glucose uptake, so that arrested cells required Atg5-dependent autophagy for long-term survival. In other cell types, a decrease in Glut1 is mediated by the thioredoxin-interacting protein (Txnip), which is induced in IL-3-dependent myeloid cells when growth factor is removed. We mutated Atg5 and Txnip by CRISPR/Cas9 and found that Atg5-dependent autophagy was not necessary for the long-term viability of cycling or arrested $\mathrm{Bax}^{-1-} \mathrm{Bakl}^{-1-}$ cells, and that Txnip was not required for the decrease in Glut1 expression in response to IL-3 withdrawal. Surprisingly, Atg5-deficient Bax/BakI double mutant cells survived for several weeks in medium supplemented with $10 \%$ fetal bovine serum (FBS), without high concentrations of added glucose or glutamine. When serum was withdrawn, the provision of an equivalent amount of glucose present in $10 \%$ FBS $(\sim 0.5 \mathrm{mM})$ was sufficient to support cell survival for more than a week, in the presence or absence of IL-3. Thus, $\mathrm{Bax}^{-1-} \mathrm{Bakl}^{-1-}$ myeloid cells deprived of growth factor consume extracellular glucose to maintain long-term viability, without a requirement for Atg5-dependent autophagy.
\end{abstract}

\section{Introduction}

Mammalian cells import a variety of extracellular nutrients to support their survival, growth, and proliferation. In vitro, cells are typically propagated in medium supplemented with

Edited by E. Baehrecke

Supplementary information The online version of this article (https:// doi.org/10.1038/s41418-019-0275-z) contains supplementary material, which is available to authorized users.

Hoanh Tran

tran.h@wehi.edu.au

1 The Walter and Eliza Hall Institute of Medical Research and the Department of Medical Biology, University of Melbourne, Melbourne, VIC, Australia

2 Murdoch Childrens Research Institute, The Royal Children's Hospital, Parkville, VIC, Australia

3 Department of Anatomy and Developmental Biology, Faculty of Medicine, Nursing and Health Sciences, Monash University, Clayton, VIC, Australia glucose, glutamine, and fetal bovine serum (FBS). To generate chemical energy, glucose can be metabolized by oxidative phosphorylation in the mitochondria or by anaerobic glycolysis. Glutamine can be used as an energy source through glutaminolysis, and can also be used, together with a multitude of factors present in serum, to allow the synthesis of essential macromolecules for cell division.

Factor-dependent myeloid (FDM) progenitor cell lines [1, 2] require the hematopoietic growth factor interleukin-3 (IL-3) to survive and multiply in culture. When IL-3 is not provided, FDM cells undergo Bax/Bak1-dependent apoptosis. FDM cells derived from $\mathrm{Bax}^{-1-} \mathrm{Bakl}^{-1-}$ mice survive in the absence of IL-3, but they undergo cell cycle arrest, similar to those over-expressing Bcl-2 [3, 4]. It has been reported that to survive longer than 4 days, IL-3-deprived $\mathrm{Bax}^{-1-} \mathrm{Bakl}^{-1-}$ cells required Atg5-dependent autophagy [4], an intracellular catabolic process that can support the survival of starved or arrested cells [5]. However, given that our Atg5-depleted Bax/ Bak1-null FDM cells survived for more than 8 days in the absence of IL-3 [6], it remains controversial whether growth factor-starved $\mathrm{Bax}^{-/-} \mathrm{Bakl}^{-/-} \mathrm{FDM}$ cells require Atg5dependent autophagy for long-term survival. 
Cells import glucose when it is available and growth factors can stimulate the amount of glucose that is consumed. $\mathrm{Bax}^{-1-} \mathrm{Bakl}^{-/-}$FDM cells arrested by IL-3 withdrawal decrease expression of the glucose transporter Glut1, which was proposed to reduce glucose uptake and metabolism [4]. Several mechanisms have been put forward to explain the regulation of expression and plasma membrane translocation of Glut1. Activation of autophagy was shown to be required for the efficient surface expression of Glut1 in mouse embryonic fibroblasts cultured under hypoxic conditions [6]. In human hepatocytes subjected to glucose starvation, a mechanism involving proteasomal degradation of the thioredoxin-interacting protein (Txnip) was required for Glut1 stabilization [7]. Moreover, it was shown that Txnip directly binds to Glut1 to promote its internalization, thus reducing Glut1 on the plasma membrane and the ability of cells to take up glucose [7].

In this study, we employed $\mathrm{Bax}^{-1-} \mathrm{Bakl^{-1- }}$ FDM cells to genetically confirm that Atg5-dependent autophagy is not required for the sustained survival of arrested cells deprived of growth factor. We also asked whether autophagy and/or Txnip are required for the reduction in Glut1 expression and glucose uptake by arrested myeloid cells.

\section{Results}

\section{$\mathrm{Bax}^{-I-} \mathrm{Bak1}^{-I-}$ myeloid cells shrink and arrest when deprived of IL-3, but survive}

FDM cells require IL-3 to survive and proliferate [2, 4, 8]. When deprived of IL-3 for 4 days, $>80 \%$ of wild-type $\mathrm{Bax}^{+/+} \mathrm{Bakl}^{+/+}$FDM cells died, as indicated by loss of plasma membrane integrity and uptake of propidium iodide (PI) (Fig. 1a and Supplementary S1A). By contrast, and consistent with the findings of Lum et al. [4], $\mathrm{Bax}^{-1-} \mathrm{Bakl}^{-1-}$ FDM cells survived in the absence of IL-3 for more than 14 days. At $48 \mathrm{~h}$ following IL-3 withdrawal, these cells shrank in size and arrested (Fig. 1b, c). This quiescent state was reversible, because when IL-3 was returned, the cells increased in size and resumed cycling. Thus, in the absence of Bax/Bak1-mediated apoptosis, FDM cells can survive for weeks without IL-3, but they shrink and arrest.

\section{Bax $^{-I-}$ Bak1 $^{-I-}$ myeloid cells arrested by deprivation of IL-3 do not require Atg5-dependent autophagy to survive}

During macroautophagy, LC3B-I is lipidated by a multiprotein complex containing Atg5 to form LC3B-II, which is incorporated into the growing autophagosome, and is commonly used as a marker of autophagy [9]. Lysates of
$\mathrm{Bax}^{-1-} \mathrm{Bakl}^{-1-}$ FDM cells, whether they were cultured in the presence or absence of IL-3, contained similar amounts of LC3B-II, suggesting that autophagy is occurring in both cycling and arrested cells (Fig. 2a). Notably, the low levels of both LC3B isoforms I and II in $\mathrm{Bax}^{-/-} \mathrm{Bakl}^{-/-}$cells cultured in serum, amino acid, and glucose-free Hank's balanced salt solution (HBSS) is indicative of a strong increase in autophagic flux, which causes the coincident degradation of LC3B proteins after autophagosomes fuse with lysosomes [9].

To determine if Atg5-dependent autophagy was needed to support the sustained survival of IL-3-starved cells, we used CRISPR/Cas9 to delete Atg5 in $\mathrm{Bax}^{-1-} \mathrm{Bakl}^{-1-}$ cells, generating $\mathrm{Bax}^{-1-} \mathrm{Bakl}^{-1-} \Delta$ Atg5 triple-knockout FDM cell clones. Western blotting confirmed in three $\mathrm{Bax}^{-/-}$ $B a k 1^{-1-} \Delta$ Atg 5 lines the absence of the LC3B-II isoform, whether they were cultured with or without IL-3, or in HBSS (Fig. 2a). Moreover, levels of LC3B-I in Bax $B a k 1^{-1-} \Delta$ Atg 5 clones remained similar across all culture conditions. These results indicate that Atg5-dependent autophagy and autophagic flux are blocked in the $\mathrm{Bax}^{-1-} \mathrm{Bakl}^{-1-} \triangle A$ tg 5 lines. After 14 days of culture without IL-3, all $\mathrm{Bax}^{-1-} \mathrm{Bakl}^{-1-} \Delta A \operatorname{tg} 5$ clones remained $\sim 80 \%$ viable (Fig. 2b). Similar to $\mathrm{Bax}^{-1-} \mathrm{Bakl}^{-1-}$ FDMs, $\mathrm{Bax}^{-1-} \mathrm{Bakl}^{-1-} \triangle$ Atg 5 cells decreased in size and arrested within $48 \mathrm{~h}$ of growth factor withdrawal (Fig. 2c, d).

These results confirm that IL-3 receptor signals are needed for $\mathrm{Bax}^{-1-} \mathrm{Bakl}^{-1-}$ FDM cells to maintain their normal size and divide, but show that Atg5-dependent autophagy is not required for their survival, whether they are cycling or are arrested by IL-3 withdrawal, consistent with our previous results using small interfering RNA (siRNA) to knockdown Atg5 in $\mathrm{Bax}^{-1-} \mathrm{Bakl}^{-/-}$FDM cells [10]. Furthermore, because culturing without IL-3 caused a similar decrease in size of the arrested $\mathrm{Bax}^{-1-} \mathrm{Bakl}^{-1-}$ cells to that of the $\mathrm{Bax}^{-1-} \mathrm{Bakl}^{-1-} \Delta$ Atg 5 cells, this shrinkage is not due to Atg5-dependent autophagy.

\section{$\mathrm{Bax}^{-I-} \mathrm{Bak1}^{-I-}$ myeloid cells arrested by IL-3 deprivation downregulate Glut1 independently of Txnip or Atg5 and survive in the absence of added glucose}

Lum et al. [4] reported that when IL-3 growth factor was removed, $\mathrm{Bax}^{-1-} \mathrm{Bakl}^{-1-} \mathrm{FDM}$ cells decreased expression of the glucose transporter Glut1 [4]. A possible mechanism for this was proposed by $\mathrm{Wu}$ et al. [7], who found that Txnip could bind to Glut1 and induce its internalization through clathrin-coated pits, thus removing it from the plasma membrane [7]. Consistent with Lum et al. [4] and Wu et al. [7], levels of Txnip increased, and those of Glut1 decreased, in lysates of $\mathrm{Bax}^{-1-} \mathrm{Bakl}^{-1-}$ cells $48 \mathrm{~h}$ following the removal of IL-3 (Fig. 3a). 
A

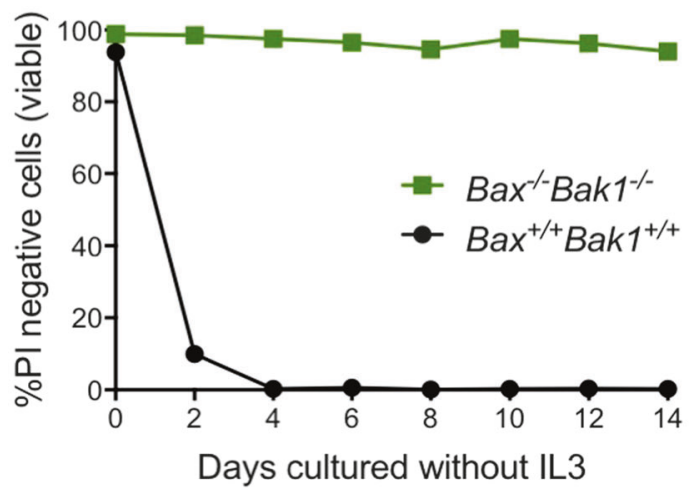

B $\quad$ Bax $^{\prime-B}$ Bak1 $^{-1-}$

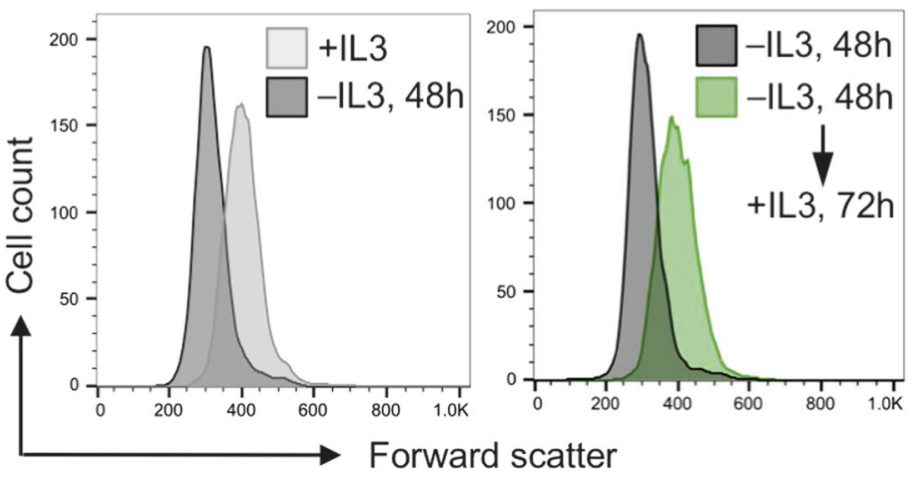

C Bax ${ }^{\prime-B a k 1^{-1-}}$
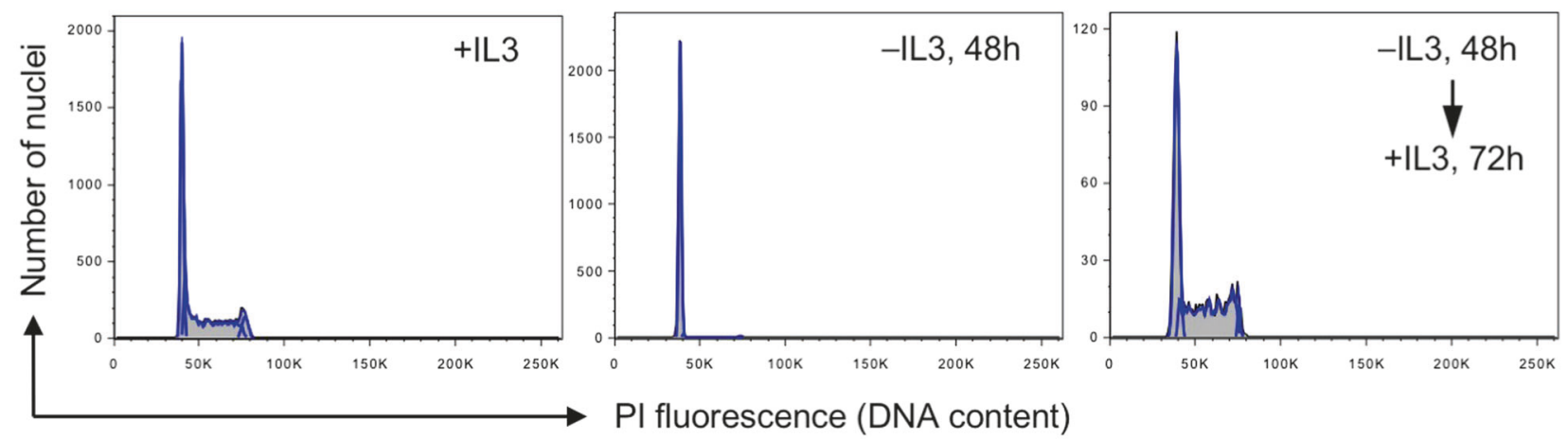

Fig. $1 \mathrm{Bax}^{-l-} \mathrm{Bakl}^{-/-}$factor-dependent myeloid (FDM) cells shrink and arrest but remain viable when cultured without interleukin-3 (IL3). a $\mathrm{Bax}^{-1-} \mathrm{Bakl}^{-1-}$ FDM cells survive long-term in the absence of IL-3. $\mathrm{Bax}^{+/+} \mathrm{Bakl}^{+/+}$wild-type (black circles) and $\mathrm{Bax}^{-1-} \mathrm{Bak1^{-1- }}$ (green squares) FDM cells were cultured without IL-3. At the indicated times, cells were harvested, resuspended in phosphate-buffered saline containing propidium iodide (PI) and analyzed by flow cytometry. b IL-3 withdrawal caused cells to shrink. PI-negative populations of $\mathrm{Bax}^{-1-} \mathrm{Bakl}^{-/-}$cells cultured for $48 \mathrm{~h}$ in the presence (light gray) or absence (dark gray) of IL-3, and the latter that had IL-3 returned for $72 \mathrm{~h}$ (green), were compared by forward scatter as an indicator of cell size. $\mathbf{c}$ IL-3 withdrawal caused cell cycle arrest, which was reversed by re-addition of IL-3. Nuclei from $\mathrm{Bax}^{-1-} \mathrm{Bakl}^{-1-}$ cells cultured as described in $\mathbf{b}$ were stained with PI to indicate DNA content by flow cytometry
To determine whether expression of Txnip caused or correlated with changes in Glut1 levels, we deleted Txnip in $\mathrm{Bax}^{-1-} \mathrm{Bakl}^{-1-}$ FDM cells using CRISPR/Cas9. Western blotting confirmed the absence of Txnip protein in three $\mathrm{Bax}^{-l-} \mathrm{Bakl}^{-1-} \Delta$ Txnip clonal lines (Fig. 3a). We found that Glut1 levels were unaffected by the deletion of Txnip, whether IL-3 was added or not, indicating that the increase in Txnip was not required for the decrease in Glut1 when cells were cultured without IL-3. Furthermore, similar to the $\mathrm{Bax}^{-1-} \mathrm{Bakl}^{-1-}$ parental cells, withdrawal of IL-3 caused $\mathrm{G}_{1}$ arrest in $B a x^{-1-}$ Bakl $^{-1-} \Delta$ Txnip cells within $48 \mathrm{~h}$ (Supplementary Fig. S1A). Because induced overexpression of FLAG-Txnip in $\mathrm{Bax}^{-1-}$ $B a k l^{-1-}$ cells had no impact on levels of Glut1 protein or cell cycle progression (Fig. 3b and Supplementary S1B), an increase in Txnip is not sufficient to reduce Glut1. Therefore, in FDM cells, the abundance of Txnip has no effect on levels of Glut1, whether they are treated with
IL-3 or not. Of note, IL-3 withdrawal caused specific downregulation of Glut1, but not Glut4, in $\mathrm{Bax}^{-/-} \mathrm{Bakl}^{-{ }^{-}}$ and $\mathrm{Bax}^{-l-} \mathrm{Bakl}^{-1-} \Delta \mathrm{Atg} 5$ clones; and levels of Glut1 were similar among proliferating Bax/Bak1-null cells of all genotypes (Fig. 3a, b and Supplementary S1C). These results indicate that although IL-3 stimulates the expression of Glut1, neither Txnip nor Atg5-dependent autophagy is required for the decrease in Glut1 when growth factor is removed from FDM cells, and neither the absence nor overexpression of Txnip affects the levels of Glut1.

Because Glut1 levels are reduced in IL-3-starved $\mathrm{Bax}^{-1-} \mathrm{Bakl}^{-1-}$ FDM cells, we asked whether glucose utilization was reduced. Proliferating $\mathrm{Bax}^{-1-} \mathrm{Bakl}^{-1-}$ cells in the presence of IL-3 responded strongly to the addition of glucose, as indicated by the increased extracellular acidification rate (ECAR, Fig. 3c), showing that they readily consumed and metabolized the added glucose. Following 
Fig. $2 \mathrm{Bax}^{-1-} \mathrm{Bakl}^{-1-} \Delta$ Atg 5

factor-dependent myeloid (FDM) cells shrink and arrest, but remain viable when interleukin-3 (IL-3) is withdrawn. a Whole cell lysates from $\mathrm{Bax}^{-l-} \mathrm{Bakl}^{-1-}$ cells and three $\mathrm{Bax}^{-1-} \mathrm{Bakl}^{-1-} \Delta$ Atg 5 clonal lines cultured in the presence of IL-3, in Hank's balanced salt solution (HBSS) for $2 \mathrm{~h}$, or in the absence of IL- 3 for 2 or $48 \mathrm{~h}$, were subjected to Western blotting. The Atg5 immunoblot demonstrates successful CRISPR/Cas9mediated deletion of Atg5. The LC3B immunoblot demonstrates lack of LC3B lipidation (isoform II) and autophagic flux (HBSS treatment) in $\triangle A \operatorname{tg} 5$ cell clones. b $\mathrm{Bax}^{-/-} \mathrm{Bakl}^{-1-} \triangle \operatorname{Atg} 5$ FDM cells survive long-term in the absence of IL-3. The indicated $\mathrm{Bax}^{-I-} \mathrm{Bak1}^{-1-} \Delta$ Atg 5 clones were cultured without IL-3 and viability was determined by propidium iodide (PI) exclusion and flow cytometry at the indicated times. c $\mathrm{Bax}^{-1-} \mathrm{Bakl}^{-1-}$ $\triangle A t g 5$ cells (clone 1 ) were cultured for $48 \mathrm{~h}$ in the presence or absence of IL-3 and PInegative populations were compared by forward scatter to indicate differences in cell size. d Cells from $\mathrm{Bax}^{-1-}$ $B a k 1^{-1-} \Delta$ Atg 5 clone 1 were cultured for $48 \mathrm{~h}$ in the presence or absence of IL-3 and then processed in PI buffer to measure DNA content by flow cytometry

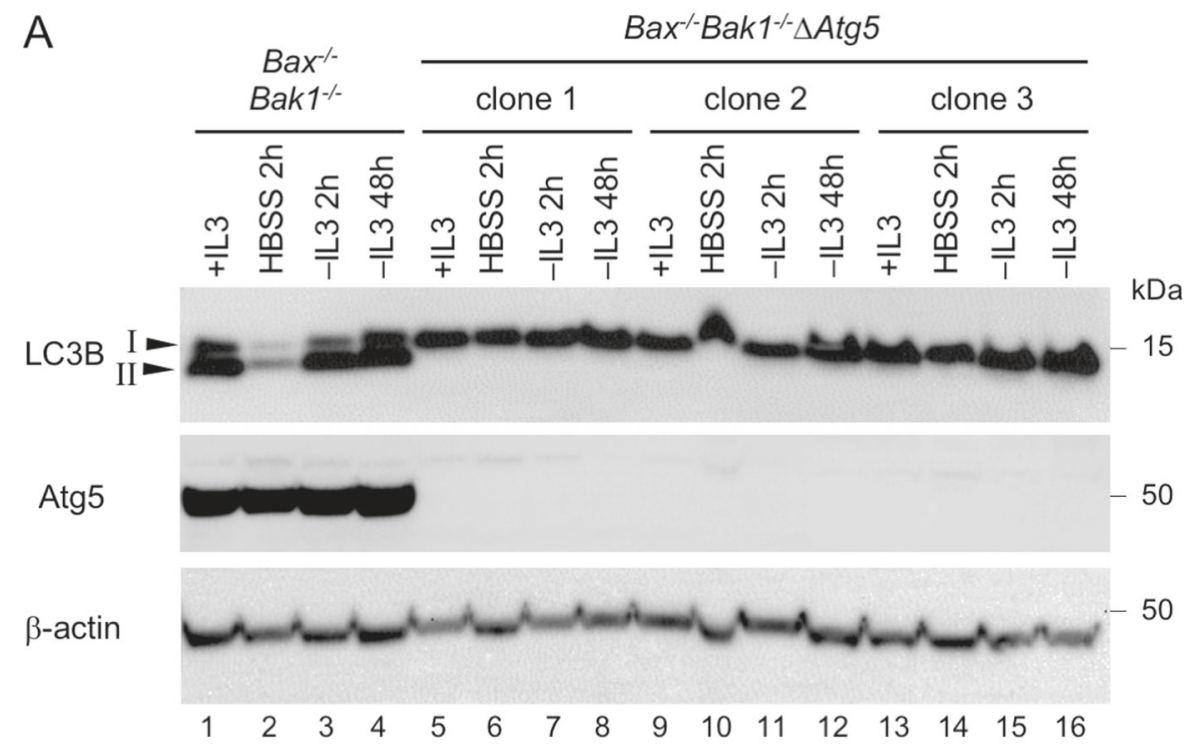

B

C Bax ${ }^{/-B a k 1 /-\triangle A t g} 5$ clone 1
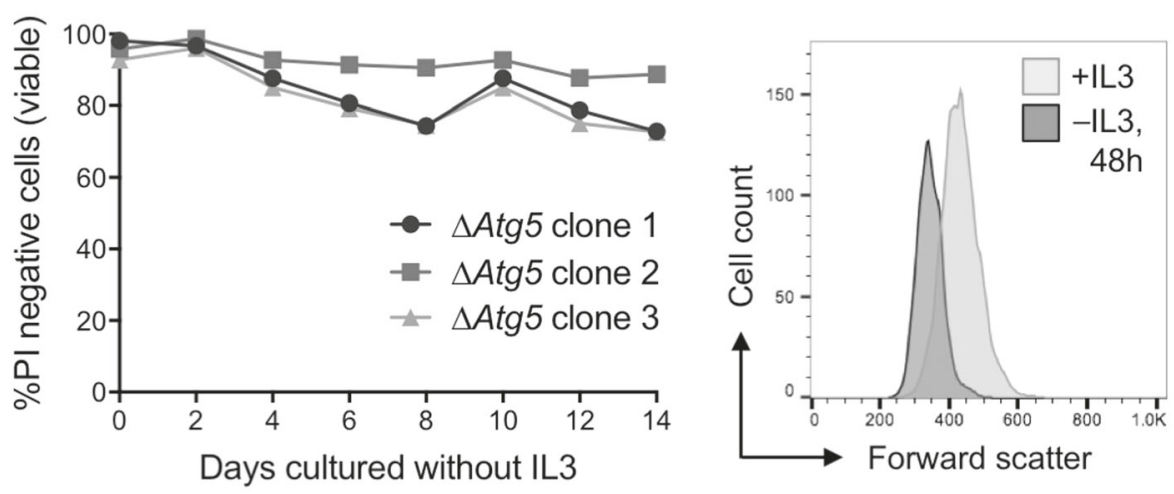

D Bax ${ }^{-1}$ Bak ${ }^{-/} \triangle$ Atg 5 clone 1

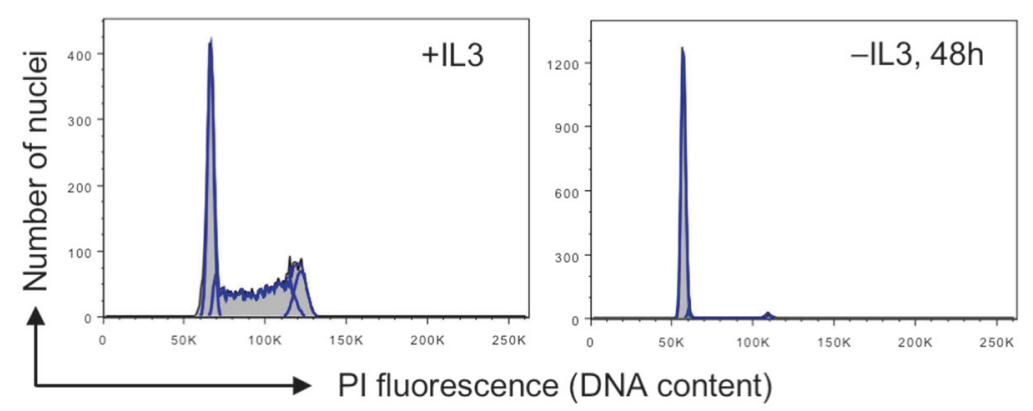

3 days of culture without IL-3, the rate of glycolysis in $\mathrm{Bax}^{-1-} \mathrm{Bakl}^{-1-}$ cells was reduced, but they nevertheless still responded to the addition of glucose. With or without IL-3, the rates of glucose metabolism in $\mathrm{Bax}^{-1-} \mathrm{Bakl}^{-1-}$ lines that also lacked Txnip or Atg5 were similar to the rates of the parental Bax/Bak1-null cells (Fig. 3c and Supplementary S1D). When cells were treated with oligomycin to block oxidative phosphorylation shortly after they reached their maximal glycolytic rate, the steady decline in ECAR continued relatively unchanged until glycolysis was inhibited with 2-deoxyglucose (2-DG), causing ECAR values to fall rapidly to baseline. These results indicate that FDM cells rely predominantly on glycolysis for energy production, and when deprived of IL-3, they retain the capacity to import and metabolize glucose, albeit at a reduced level.

Because IL-3-starved $\mathrm{Bax}^{-1-} \mathrm{Bakl}^{-1-}$ FDMs took up and metabolized glucose, we hypothesized that this was sufficient to support their sustained survival despite the decrease 


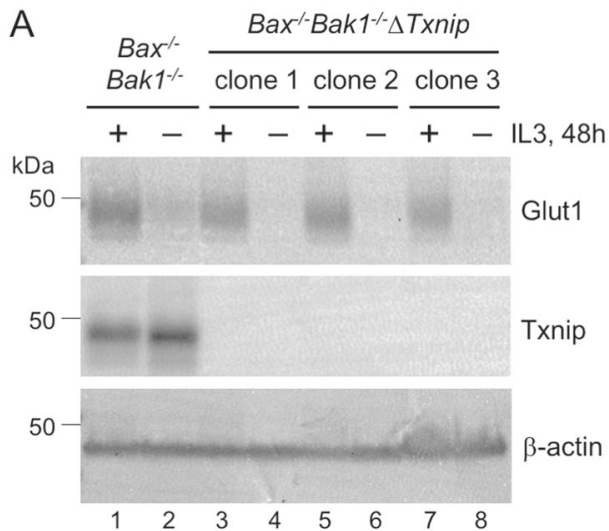

C $\quad$ Bax $^{\prime-B a k 1^{-1}}$

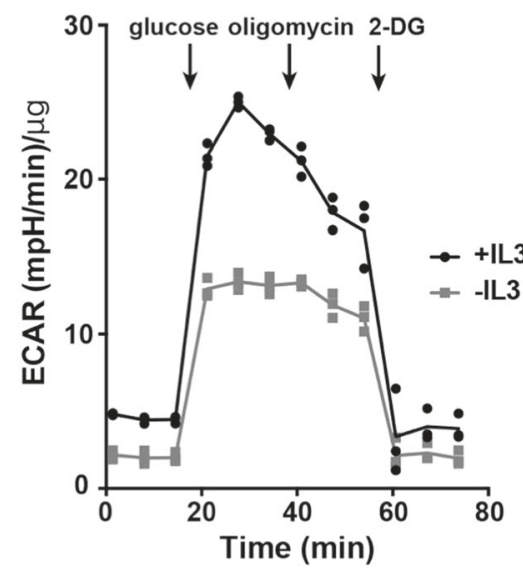

D Bax ${ }^{\prime-B a k 1^{-1}}$

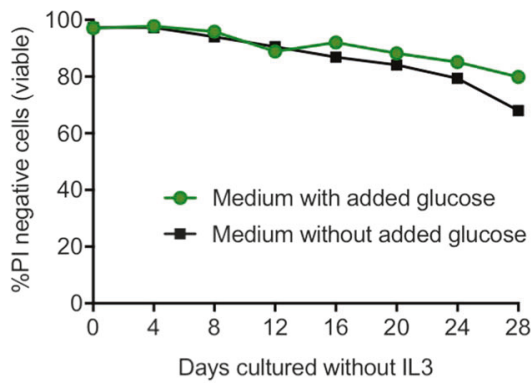

Fig. $3 \mathrm{Bax}^{-1-} \mathrm{Bakl}^{-1-}$ factor-dependent myeloid (FDM) cells arrested by interleukin-3 (IL-3) deprivation survive in the absence of added glucose. a Thioredoxin-interacting protein (Txnip) is not required for the decrease in Glut1 following IL-3 withdrawal. Whole cell lysates from $\mathrm{Bax}^{-1-} \mathrm{Bakl}^{-1-}$ and three independent $\mathrm{Bax}^{-1-} \mathrm{Bakl}^{-1-} \Delta$ Txnip FDM cell clones cultured for $48 \mathrm{~h}$ in the presence or absence of IL-3 were analyzed by Western blotting to detect Glut1 and Txnip protein. b Forced expression of Txnip is not sufficient to decrease Glut1 protein levels. Independent $\mathrm{Bax}^{-1-} \mathrm{Bakl}^{-1-}$ FDM clones bearing a doxycycline (dox)-inducible FLAG-Txnip construct or empty vector control were cultured for $72 \mathrm{~h}$ in the absence or presence of dox $(100 \mathrm{ng} / \mathrm{mL})$. Whole cell lysates were prepared and analyzed by Western blotting to detect

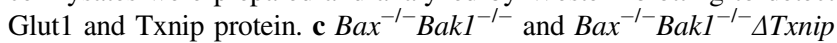
cells can take up and metabolize glucose. Cells cultured for $72 \mathrm{~h}$ in the presence or absence of IL-3 were analyzed on the Seahorse bioanalyzer to measure the extracellular acidification rate (ECAR) as an indicator of glucose metabolism. The increased ECAR following the addition of
B Bax ${ }^{-B}$ Bak $1^{-}$; Txnip overexpression

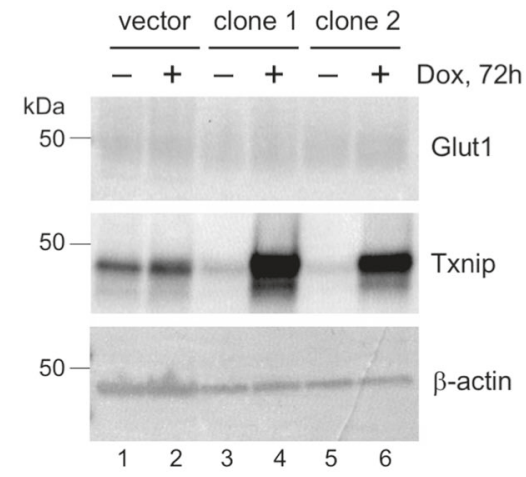

Bax ${ }^{-B}$ Bak ${ }^{-1-} \Delta$ Txnip clone 1

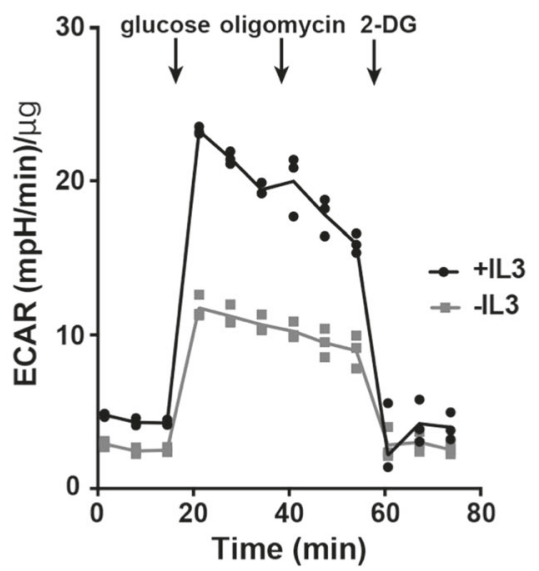

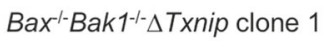

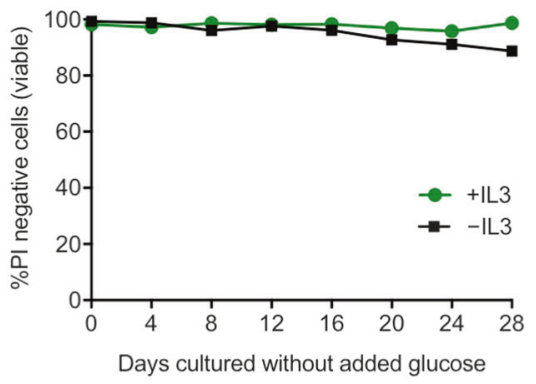

glucose signifies increased glycolytic flux in cells. Oligomycin inhibits mitochondrial ATP synthase and the change in ECAR upon its addition represents the glycolytic reserve capacity of cells. Glycolysis is inhibited by 2-deoxyglucose (2-DG), so upon its addition, the ECAR values are produced from non-glycolytic sources. Equal numbers of cells were seeded for analysis. To correct for the reduced size of IL-3starved cells, protein concentration was assayed and the ECAR values were normalized to $1 \mu \mathrm{g}$ total protein per sample. Curves represent the mean of three replicate samples depicted as solid symbols for each timepoint. d $\mathrm{Bax}^{-/-} \mathrm{Bakl}^{-1-}$ and $\mathrm{Bax}^{-I-} \mathrm{Bakl}^{-1-}$ ATxnip cells deprived of IL-3 survive for several weeks in the absence of added glucose. Cells were cultured without or with IL-3 in the medium supplemented with $10 \%$ fetal bovine serum (FBS), $4 \mathrm{mM}$ glutamine, and $5.5 \mathrm{mM}$ glucose (medium with added glucose) or in medium supplemented with $10 \%$ FBS and $4 \mathrm{mM}$ glutamine (medium without added glucose). Cell viability was monitored by propidium iodide (PI) exclusion and flow cytometry at the indicated times 
in Glut1. FDM cells were routinely cultured in Dulbecco's modified Eagle's medium (DMEM) supplemented with $4 \mathrm{mM}$ glutamine, $5.5 \mathrm{mM}$ glucose, and $10 \%$ fetal bovine serum (FBS). The 10\% FBS is estimated to also contain $\sim 0.5 \mathrm{mM}$ glucose (Supplementary Fig. S1E). To test their requirement for glucose, FDM cells were cultured in DMEM supplemented with $4 \mathrm{mM}$ glutamine and $10 \% \mathrm{FBS}$, but lacking the added $5.5 \mathrm{mM}$ glucose. Surprisingly, $>80 \%$ of IL-3-starved $\mathrm{Bax}^{-l-} \mathrm{Bakl}^{-1-}$ and $\mathrm{Bax}^{-l-} \mathrm{Bakl}^{-l-} \Delta$ Txnip cells remained viable for 3 weeks in culture without added glucose (Fig. 3d). Moreover, when IL-3 was present, these cells were able to proliferate (Supplementary Fig. S1F). These results suggest that $\mathrm{Bax}^{-1-} \mathrm{Bakl}^{-1-}$ FDM cells do not require high concentrations of glucose to maintain longterm viability, whether IL-3 is present or not, and that they consume the glucose in FBS and the added glutamine to survive or to proliferate with IL-3.

\section{$\mathrm{Bax}^{-I-} \mathrm{Bak1}^{-1-}$ myeloid cells require glutamine to proliferate, but can survive in its absence for weeks}

When glucose is limiting, lymphoid cells metabolize glutamine to survive and proliferate [11]. We therefore asked whether IL-3-dependent myeloid cells exhibited similar requirements for glutamine. In medium supplemented with $10 \%$ FBS but without added glucose or glutamine, with or without IL-3, $>95 \%$ of wild-type $\mathrm{Bax}^{+/+} \mathrm{Bakl}^{+/+}$FDM cells died as indicated by uptake of PI by day 4 (Supplementary Fig. S2A), and consistent with their death being due to apoptosis, the nuclei of the cells had sub- $2 n$ DNA (Fig. 4a). Apoptosis was Bax/Bak1-dependent, because Bax/Bak1null cells, including clones also lacking Atg5, did not die when cultured in medium without added glucose and glutamine, but they arrested instead, even when IL-3 was provided (Fig. 4a). When cultured with neither added glucose nor glutamine, in the presence or absence of $\mathrm{IL}-3,>80 \%$ of the arrested $\mathrm{Bax}^{-l-} \mathrm{Bakl}^{-/-}$and $\mathrm{Bax}^{-l-} \mathrm{Bakl}^{-l-} \Delta$ Atg 5 cells survived for more than 12 days (Fig. 4b and Supplementary S2B).

When $\mathrm{Bax}^{-1-} \mathrm{Bakl}^{-1-}$ cells were starved of added glucose and glutamine, most arrested in $\mathrm{G}_{1}$ with $2 n$ DNA, but some arrested in $\mathrm{G}_{2} / \mathrm{M}$ with $4 n$ DNA (Fig. $4 \mathrm{a}$ ). When glutamine was added back to these arrested cells after 7 days, they resumed cycling within $48 \mathrm{~h}$ in the presence of IL-3, whereas adding back glucose had no effect (Supplementary Fig. S2C). These results indicate that IL-3-stimulated $\mathrm{Bax}^{-1-} \mathrm{Bakl}^{-1-}$ myeloid cells require glutamine to proliferate, but can survive for weeks in its absence. Because $\mathrm{Bax}^{-1-} \mathrm{Bakl}^{-1-} \Delta$ Atg 5 cells behaved similarly to $\mathrm{Bax}^{-1-} \mathrm{Bakl}^{-1-}$ parental cells, Atg5-dependent autophagy is not required for the sustained survival of IL-3-deprived $\mathrm{Bax}^{-/-} \mathrm{Bakl}^{-1-}$ FDMs, even in cultures without high levels of added glucose and glutamine.
$\mathrm{Bax}^{-l-} \mathrm{Bak1}^{-1-}$ myeloid cells arrested by glutamine deprivation shrink in a manner independent of Atg5-mediated autophagy

Because $\mathrm{Bax}^{-1-} \mathrm{Bakl}^{-1-}$ and $\mathrm{Bax}^{-/-} \mathrm{Bakl}^{-1-} \Delta$ Atg 5 cells arrested by IL-3 withdrawal decreased in size (Figs. 1b, 2c), we asked whether cells arrested by glutamine withdrawal also shrink. In medium supplemented with $10 \%$ FBS, but lacking added glucose and glutamine, IL-3-treated $\mathrm{Bax}^{-l-} \mathrm{Bakl}^{-1-}$ and $\mathrm{Bax}^{-1-} \mathrm{Bakl}^{-l-} \Delta$ Atg 5 cells showed a gradual decrease in size to almost $1 / 3$ of their original volume over a 20-day period (Fig. 5). Without IL-3, the shrinkage was more acute and cells reached $\sim 1 / 3$ of their original volume within 7 days. These results suggest that IL-3 provided a signal to $\mathrm{Bax}^{-1-} \mathrm{Bakl}^{-1-}$ myeloid cells arrested by glutamine deprivation to maintain a large size, and confirm that the shrinkage of these cells upon IL-3 and/ or nutrient withdrawal do not require Atg5-dependent autophagy.

\section{Withdrawal of IL-3 or glutamine caused reduced expression of $\mathrm{Mcl}-1$ and key regulators of cell cycle progression}

To elucidate how growth factor and nutrient deprivation impacted FDM cell survival and proliferation, we performed Western blotting to determine protein levels of apoptotic and cell cycle regulators. We found that levels of the pro-survival protein Mcl-1 were markedly reduced in $\mathrm{Bax}^{-1-} \mathrm{Bakl}^{-1-}$ and $\mathrm{Bax}^{-1-} \mathrm{Bakl}^{-1-} \Delta$ Atg 5 cells after 3 days in culture without added glucose and glutamine (Fig. 6a), suggesting that the decrease in normal levels of Mcl-1 allowed activation of Bax/Bak1 and the apoptosis of wildtype FDM cells observed in Fig. 4a. Consistent with this notion, addition of a specific Mcl-1 inhibitor S63845 [12] to $\mathrm{Bax}^{+/+} \mathrm{Bakl}^{+/+}$cells was sufficient to cause significant apoptosis within $24 \mathrm{~h}$, even when the cells were cultured with IL-3 in medium supplemented with glucose, glutamine, and 10\% FBS (Fig. 6b).

As well as causing arrest, IL-3 withdrawal reduced c-Myc protein to barely detectable levels in both $\mathrm{Bax}^{-1-} \mathrm{Bakl}^{-1-}$ and $\mathrm{Bax}^{-1-} \mathrm{Bakl}^{-1-} \Delta$ Atg 5 cells (Fig. 6a). Cyclin-dependent kinase 4 (Cdk4) and cyclin D3 are key drivers of cell cycle progression in hematopoietic cell lines $[13,14]$, and these proteins were also markedly reduced in the IL-3-starved, Bax/Bak1-deficient myeloid cells, suggesting a mechanism for their arrest (Figs. 1c, 2d). Withdrawal of glutamine from these cells also caused cell cycle arrest, even in the presence of IL-3 (Fig. 4a). Under these conditions, IL-3 was able to stimulate the expression of c-Myc and Cdk4, but the levels of these proteins were significantly lower than in the cells cultured with both glutamine and IL-3 (Fig. 6a). The transcription factor Atf4 
A +Glutamine -Glutamine -Glucose

+IL3

+ IL3
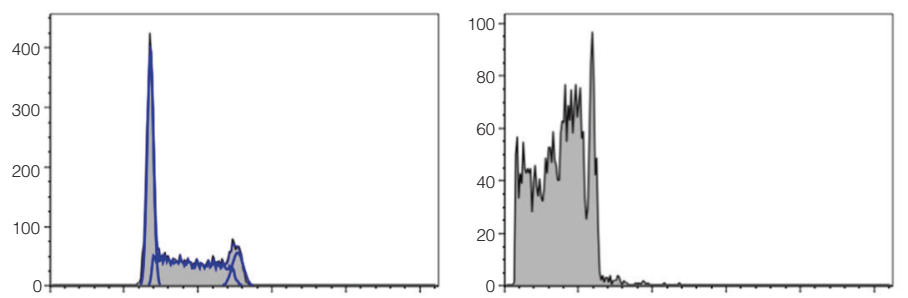

-IL3
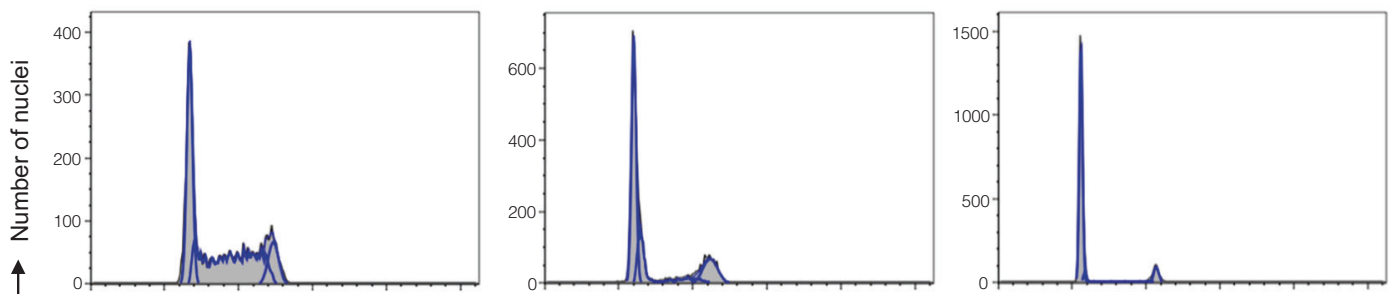

Bax - Bak1\%
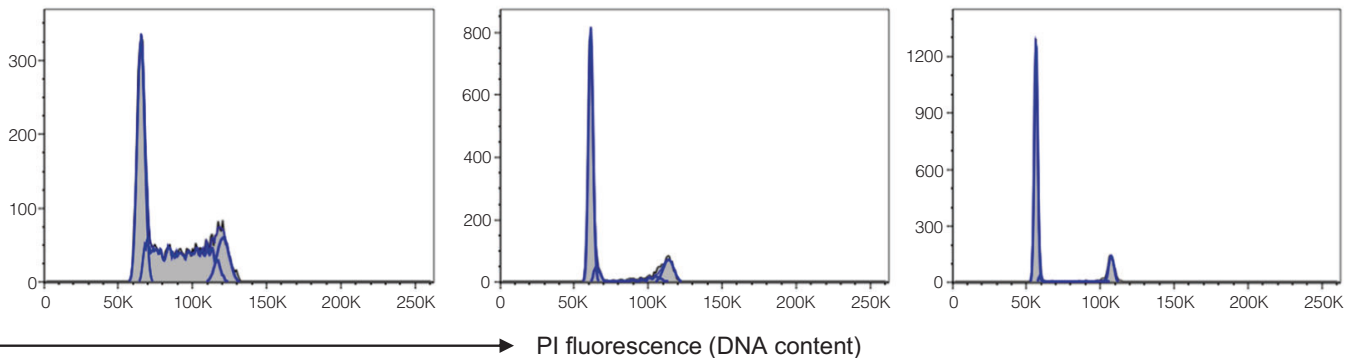

Bax $^{-/-B a k 1 /-\triangle A t g} 5$ clone 1

$\mathrm{B}$

+ IL3

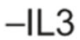

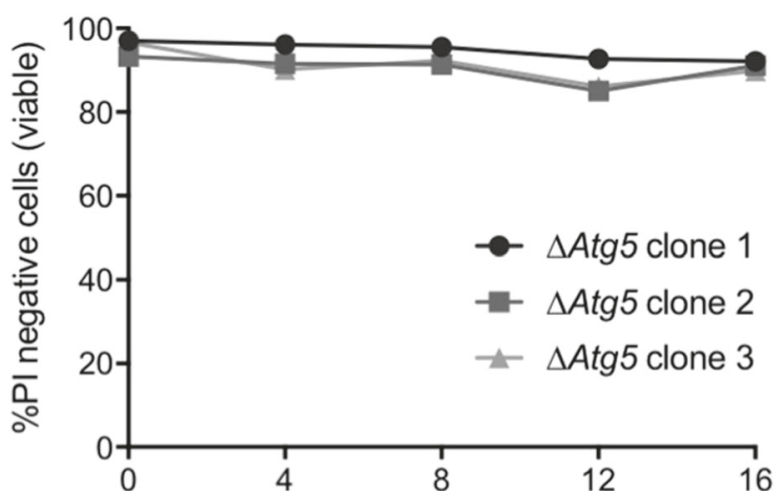

Days cultured without added glucose and glutamine

Fig. 4 When starved of glutamine, $\mathrm{Bax}^{+/+} \mathrm{Bakl}^{+/+}$factor-dependent myeloid (FDM) cells undergo apoptosis, whereas $\mathrm{Bax}^{-1-} \mathrm{Bakl^{-1 }}$ cells arrest, but can survive for weeks. a $\mathrm{Bax}^{+/+} \mathrm{Bakl}^{+/+}$cells undergo apoptosis in the absence of glutamine (upper panels), whereas $\mathrm{Bax}^{-/-} \mathrm{Bakl}^{-1-}$ and $\mathrm{Bax}^{-1-} \mathrm{Bakl}^{-1-} \Delta \mathrm{Atg} 5$ cells survive in the absence of glutamine, but arrest even when interleukin-3 (IL-3) is present (lower panels). Cells were cultured in medium supplemented with $10 \%$ fetal bovine serum (FBS), with or without IL-3 and $4 \mathrm{mM}$ glutamine, in the absence of added glucose, for 4 days. Cells were processed in

accumulates in response to a variety of cellular stresses including amino acid starvation [15]. In glutamine-starved $\mathrm{Bax}^{-1-} \mathrm{Bakl}^{-1-}$ and $\mathrm{Bax}^{-1-} \mathrm{Bakl}^{-1-} \Delta$ Atg 5 cells, Atf4 levels increase strongly, but intriguingly only in the presence of

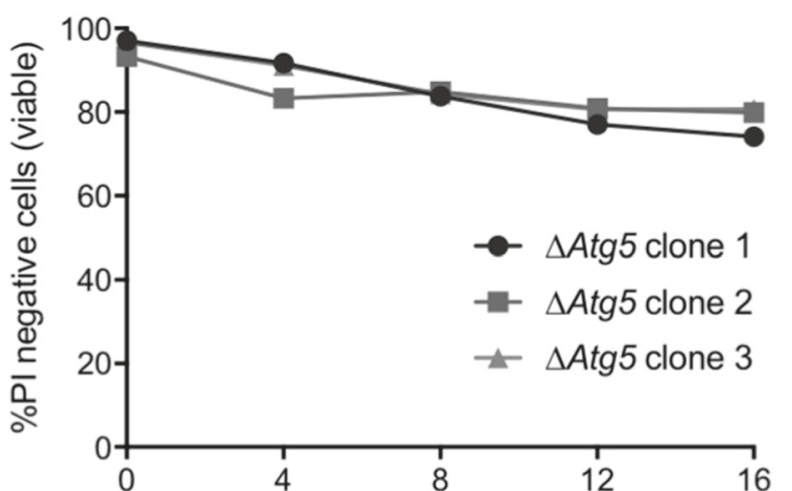

Days cultured without added glucose and glutamine

propidium iodide (PI) buffer to assess DNA content by flow cytometry. Note the absence of cells in the $\mathrm{S}$ phase when Bax/Bak1-null cells were cultured without the addition of glutamine. b $\mathrm{Bax}^{-1-}$ $B a k 1^{-l-} \Delta A \operatorname{tg} 5$ cells survive for weeks in the absence of glutamine.

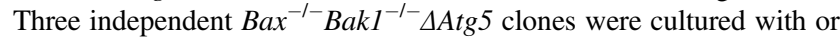
without IL-3, in medium supplemented with $10 \%$ FBS, without added glucose or glutamine. At the indicated times, cells were assayed for viability by PI exclusion and flow cytometry

IL-3. These results indicate that the signal transduction pathway activated by ligation of the IL-3 receptors remains largely intact in cells cultured without supplemented glutamine, and can stimulate the cells to remain large, but that 


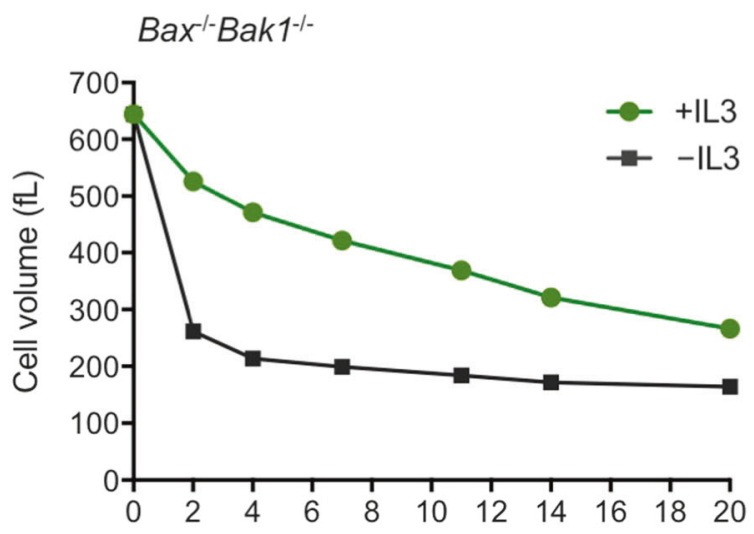

Days cultured without added glucose and glutamine

\section{Bax ${ }^{-1-B a k 1 /-\triangle A t g} 5$ clone 1}

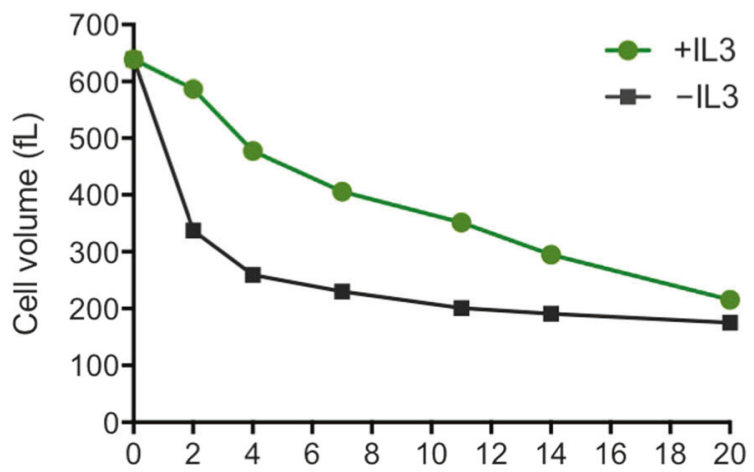

Days cultured without added glucose and glutamine

Fig. 5 Withdrawal of interleukin-3 (IL-3) and/or glutamine caused cell shrinkage independent of Atg5-mediated autophagy. Bax ${ }^{-l-} B a k 1^{-1-}$ and $\mathrm{Bax}^{-1-} \mathrm{Bakl}^{-1-} \Delta$ Atg 5 cells were cultured in medium supplemented with $10 \%$ fetal bovine serum (FBS), with or without IL-3, in the absence of added glucose and glutamine. At the indicated times, cell volume was measured in a Coulter-based CASY cell counter

glutamine is essential for high levels of c-Myc, Cdk4, and cyclin D3 expression, and for the cells to divide.

\section{$\mathrm{Bax}^{-I-} \mathrm{Bak1}^{-1-}$ myeloid cells consume extracellular glucose to maintain long-term viability}

The Bax/Bak1-null cells cultured without high concentrations of added glucose and glutamine would need a source of energy to survive (Fig. 4b and Supplementary S2B), so we tested whether they were obtaining it from the supplemented FBS. In IL-3-containing medium lacking added glucose, glutamine, and FBS, all $\mathrm{Bax}^{-1-} \mathrm{Bakl}^{-1-}$ and $\mathrm{Bax}^{-1-}$ $B a k 1^{-1} \Delta A t g 5$ cells died after 2 days (Fig. 7a). In the absence of serum, we asked if adding back glutamine or glucose alone was sufficient to support cell survival. While $<40 \%$ of cells cultured in medium supplemented with $4 \mathrm{mM}$ glutamine remained viable after 2 days (and all died within 4 days, Supplementary Fig. S3A), $>90 \%$ of cells cultured with
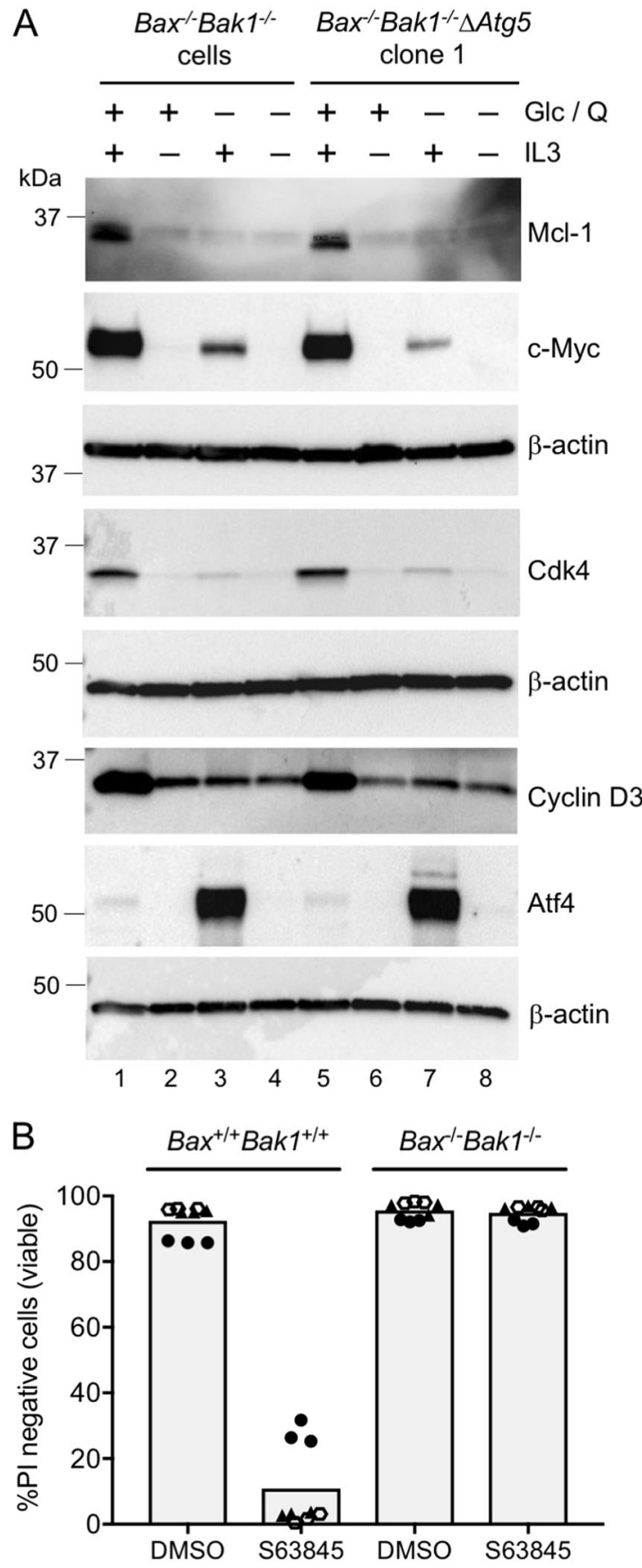

$5.5 \mathrm{mM}$ glucose survived for more than 6 days (Fig. $7 \mathrm{a}$ and Supplementary S3B). In IL-3-starved cultures, we observed a similar dependence on glucose, but not glutamine, for cell viability (Fig. 7b). Strikingly, $0.5 \mathrm{mM}$ glucose only, an equivalent amount present in $10 \%$ FBS, was sufficient to support the survival of $>80 \%$ of IL-3-deprived $\mathrm{Bax}^{-1-}$ $\mathrm{Bakl}^{-1-}$ and $\mathrm{Bax}^{-1-} \mathrm{Bakl}^{-1-} \Delta \mathrm{Atg} 5$ cells (Fig. 7b) for at least 1 week (Fig. 7c). Collectively, these results suggest that in the absence of growth factor, $\mathrm{Bax}^{-1-} \mathrm{Bakl}^{-1-}$ myeloid cells consume extracellular glucose to maintain long-term viability, without the need to invoke Atg5-dependent autophagy. 
Fig. 6 Withdrawal of interleukin-3 (IL-3) or glutamine reduced the expression of Mcl-1 and several key regulators of cell cycle progression. a $\mathrm{Bax}^{-1-} \mathrm{Bakl}^{-l-}$ cells and $\mathrm{Bax}^{-l-} \mathrm{Bakl}^{-l-} \Delta \mathrm{Atg} 5$ clone 1 were cultured for $72 \mathrm{~h}$ in medium supplemented with $(+)$ or without $(-)$ added glucose $(\mathrm{Glc})$ and glutamine $(\mathrm{Q})$, as indicated, in the presence or absence of IL-3 (+/-). Whole cell lysates were prepared and analyzed by Western blotting to detect the indicated proteins. Three independent membranes were used for immunoblotting, and $\beta$-actin loading control blots for each are shown. Membrane \#1: anti-Mcl-1 and anti-c-Myc; membrane \#2: anti-Cdk4; membrane \#3: anti-cyclin D3 and anti-Atf4. b $\mathrm{Bax}^{+/+} \mathrm{Bakl}^{+/+}$and $\mathrm{Bax}^{-/-} \mathrm{Bakl}^{-/-}$cells cultured in complete medium with IL-3 were treated with dimethyl sulfoxide (DMSO; vehicle control) or $10 \mu \mathrm{M}$ of the Mcl-1 inhibitor S63845 for $24 \mathrm{~h}$. Cells were harvested and viability determined by propidium iodide (PI) exclusion and flow cytometry. Bars depict the mean of three independent experiments represented by the three different symbols, performed in triplicate. The experiment represented by the solid circles was performed with S63845 synthesized by SYNthesis Med Chem. Experiments represented by the solid triangles and open hexagons were performed with S63845 synthesized by Active Biochem (see Materials and methods)

\section{Discussion}

We have genetically eliminated Atg5 expression in IL-3dependent $\mathrm{Bax}^{-1-} \mathrm{Bakl}^{-1-}$ myeloid (FDM) cells and tested their ability to maintain survival in the absence of growth factor. Unlike Lum et al. [4], who concluded that Atg5dependent autophagy was necessary to sustain the survival of IL-3-deprived $\mathrm{Bax}^{-l-} \mathrm{Bakl}^{-1-}$ FDM cells beyond 4 days, our results demonstrate that canonical autophagy pathways are not required to support the long-term viability of these cells (Figs. 2, 4, 5, 7) [10]. We generated IL-3-dependent FDM lines by co-culturing E14.5 fetal liver single-cell suspensions from $\mathrm{Bax}^{-1-} \mathrm{Bakl}^{-l-}$ embryos with fibroblasts expressing a $H o x B 8$ retrovirus (to immortalize the cells) in the presence of IL-3 [16]. Lum et al. [4] obtained IL-3-dependent myeloid progenitors from the bone marrow of adult $\mathrm{Bax}^{-1-} \mathrm{Bakl}^{-1-}$ mice, but did not specify how these cells were immortalized. It is plausible that differences in the age of donors, organ of origin, or immortalization protocols used to generate IL-3dependent myeloid lines account for the different requirements for autophagy between our lines and those used by Lum et al. [4] when IL-3 was withdrawn. Furthermore, cell lines in culture can accumulate genetic and epigenetic changes [17], so we cannot exclude the possibility that such changes have altered the requirement of these lines for autophagy to survive when arrested. We also cannot exclude the possibility that the siRNAs used by Lum et al. [4] affected cell survival indirectly, for example, by induction of interferons. Nevertheless, because our IL-3-dependent $\mathrm{Bax}^{-1-}$ $B a k 1^{-1-}$ FDM lines did not require Atg5-dependent autophagy to survive when IL-3 was withdrawn, it is premature to generalize the conclusion of Lum et al. [4] that autophagy is essential for maintaining cell survival following growth factor withdrawal.
A

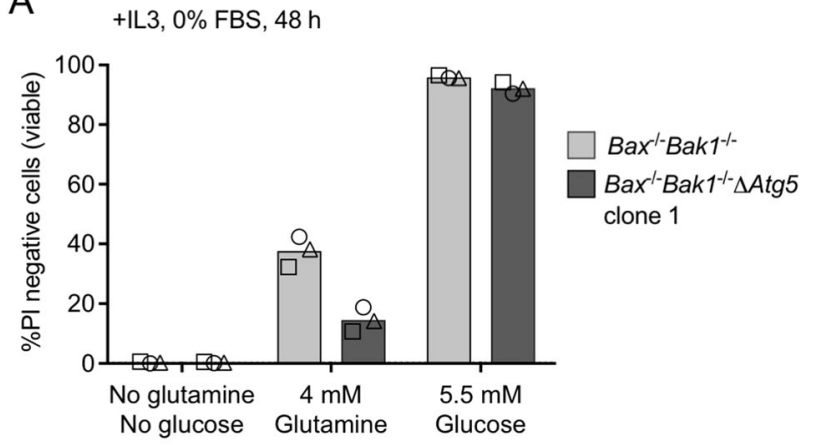

B
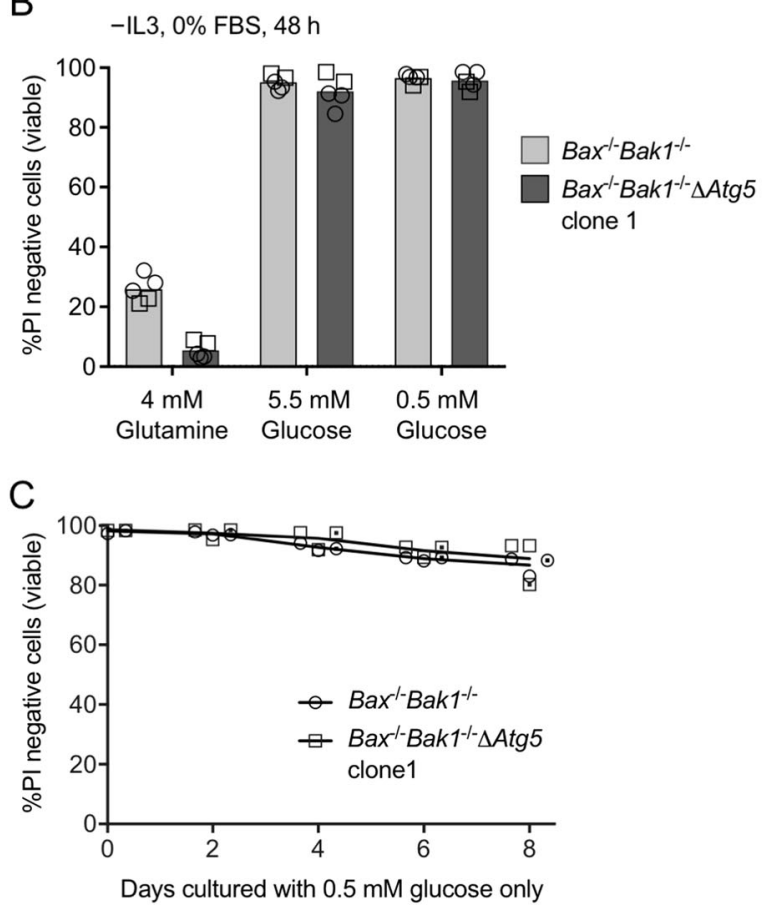

Fig. 7 In the absence of Atg5-dependent autophagy, interleukin-3 (IL-3)-deprived $\mathrm{Bax}^{-1-} \mathrm{Bakl}^{-1-}$ myeloid cells consume extracellular glucose to maintain long-term viability. a $\mathrm{Bax}^{-1-} \mathrm{Bakl}^{-1-}$ cells and $\mathrm{Bax}^{-1-} \mathrm{Bakl}^{-1-} \Delta$ Atg 5 clone 1 were cultured with IL-3 in the absence of fetal bovine serum (FBS) for $48 \mathrm{~h}$ in medium without or with the specified concentration of glutamine and/or glucose. Cells were assayed for viability by propidium iodide (PI) exclusion and flow cytometry. Bars represent the average of three independent experiments (depicted by the three different symbols). b $\mathrm{Bax}^{-1-} \mathrm{Bakl}^{-1-}$ cells and $\mathrm{Bax}^{-l-} \mathrm{Bakl}^{-I-} \Delta \mathrm{Atg} 5$ clone 1 were cultured without IL-3 or fetal bovine serum (FBS) for $48 \mathrm{~h}$ in medium with the specified concentration of glutamine or glucose. Cells were assayed for viability by PI exclusion and flow cytometry. Bars represent the average of two independent experiments (depicted by the two different symbols) performed with technical replicates as indicated. c $\mathrm{Bax}^{-1-} \mathrm{Bakl^{-1- }}$ and $\mathrm{Bax}^{-1-} \mathrm{Bakl}^{-1-} \Delta$ Atg 5 cells were cultured in medium supplemented with $0.5 \mathrm{mM}$ glucose, without IL-3, glutamine, or FBS. At the indicated times, cells were assayed for viability by PI exclusion and flow cytometry. The curves connect the average values of data points derived from two independent experiments (depicted by the two different symbols) performed with technical replicates or without (dotted symbols) as indicated 
We were able to confirm the observation that culture of $\mathrm{Bax}^{-/} \mathrm{Bakl}^{-1-}$ FDM cells without IL-3 reduced the levels of the glucose transporter Glut1 [4], and wondered if the mechanism for reduction of Glut1 would be similar to that described by $\mathrm{Wu}$ et al. [7], who found that Txnip could reduce the levels of Glut1. Although we confirmed the reported inverse correlation between levels of Txnip and Glut1, Txnip is neither required nor sufficient for IL-3 to regulate levels of Glut1 in FDMs (Fig. 3). It remains possible that the Txnip-mediated downregulation of Glut1 is a mechanism specific to human hepatocytes and other cell types in response to glucose availability [7]. Canonical autophagy was shown to be required for the efficient surface expression of Glut1 [6]. Compared to parental $\mathrm{Bax}^{-1-}$ $\mathrm{Bakl}^{-1-}$ FDM cells, our Atg5-deficient $\mathrm{Bax}^{-1-} \mathrm{Bakl}^{-1-}$ lines had similar levels of Glut1, decreased Glut1 to a similar extent when cultured without IL-3, and showed similar levels of glucose uptake to the parental cells when cultured with IL-3 or without. Therefore, in FDM cells, Atg5-dependent autophagy is not needed to maintain normal levels of Glut1, and does not affect the ability of IL-3starved cells to take up and metabolize glucose.

Consistent with the requirement of glutamine for lymphoid cell survival [11], we found that wild-type FDM cells died following glutamine deprivation (Fig. 4). Surprisingly, glutamine was not required to support the survival of Bax/ Bak1-null FDM cells in serum-containing cultures, and glutamine-deprived cells maintained a large size in the presence of IL-3, but arrested. This suggests that glutamine provided the source of amino acids needed for cell division, but that in its absence, $\mathrm{Bax}^{-1-} \mathrm{Bakl}^{-1-}$ cells import and metabolized the glucose present in serum to maintain viability. We also found that the shrinkage of FDM cells arrested by glutamine and/or IL-3 withdrawal occurred independently of Atg5-mediated autophagy (Fig. 5), consistent with Hecht et al. [18], who reported that the acute shrinkage of $\mathrm{B}$ and $\mathrm{T}$ lymphocytes following growth factor withdrawal occurred before the induction of autophagy.

In the absence of high levels of glutamine and glucose, pathways activated by IL-3 could still converge to induce the expression of c-Myc in Bax/Bak1-null FDM cells, and although this response was blunted, the arrested cells maintained a relatively large size for at least 1 week (Fig. 5). The transcription factor Atf4 was strongly induced by IL-3 in glutamine-starved cells, but it is unclear how or why signaling from the IL-3 receptor leads to increased Atf4 production. Although Atf4 was shown to activate the expression of several autophagy genes to promote cell survival [19], we have not been able to confirm that its accumulation induced LC3B lipidation in the glutamine-starved FDM cells. That IL-3 also induced Atf4 expression in Atg5-deficient $\mathrm{Bax}^{-1-} \mathrm{Bakl}^{-1-}$ cells following glutamine deprivation (Fig. 6) suggests that Atf4 does not promote canonical autophagy to maintain cell viability under these conditions. Moreover, cells starved of both IL-3 and glutamine showed no detectable expression of Atf4, yet survived for weeks.

In the absence of IL- 3 and high concentrations of added glucose and glutamine, Atg5-deficient $\mathrm{Bax}^{-l-} \mathrm{Bakl}^{-1-}$ cells remained viable for weeks in serum-containing medium, and their rapid death in glucose-free cultures was consistent with the hypothesis that they took up and used the glucose present in serum to survive (Fig. 7). That these cells predominantly generate chemical energy through glycolysis (Fig. 3) was also consistent with their ability to consume only diluted concentrations of glucose to remain viable for at least a week. Serum-starved Bax/Bak1-null cells supplemented with high concentrations of glucose and glutamine survived for several weeks, but arrested, with or without IL-3 (data not shown). Collectively, our work suggests that in the absence of growth factor, $\mathrm{Bax}^{-/-} \mathrm{Bakl}^{-1-}$ FDM cells, including mutant lines lacking Atg5-dependent autophagy, import extracellular glucose and amino acids to maintain long-term viability. The metabolic requirement for glucose and amino acids is a mechanism to support cell survival, even in cultures where levels of these nutrients are not optimal for cell proliferation, and the reduced levels of c-Myc, Cdk4, and cyclin D3, combined with possibly altered levels of other cell cycle regulators, could explain why growth factor and/or nutrientstarved $\mathrm{Bax}^{-1-} \mathrm{Bakl}^{-1-}$ FDM cells arrested (Fig. 8).

\section{Materials and methods}

\section{Cell culture}

Wild-type $\mathrm{Bax}^{+/+} \mathrm{Bakl}^{+/+}$and $\mathrm{Bax}^{-/-} \mathrm{Bakl}^{-/-}$IL-3-dependent mouse myeloid progenitor (FDM) cell lines have been described [16]. We routinely test our cells for mycoplasma contamination. Cells were cultured in DMEM (Thermo Fisher Scientific, Cat\# 11885-084; containing $5.55 \mathrm{mM}$ D-glucose and $4 \mathrm{mM}$ L-glutamine) supplemented with 10\% FBS (Sigma, Cat\# F9423) and $0.25 \mathrm{ng} / \mathrm{mL}$ recombinant murine IL-3 (PeproTech, Cat\# 213-13) in a $37^{\circ} \mathrm{C}$ humidified incubator with $10 \% \mathrm{CO}_{2}$. Cells were deprived of IL-3, glucose, glutamine, glucose and glutamine, or varying concentrations of FBS, by washing three times with medium that lacked those nutrients, and then resuspended in the same medium for analysis at the indicated time points. Unless indicated otherwise, $1 \times 10^{5}$ cells were seeded in $1 \mathrm{~mL}$ of the specified medium per well of a 24-well tissue culture plate (Corning, Cat\# 353047), and one well was analyzed for each timepoint. Media were not renewed or topped up during time-course experiments. To prevent cells from sticking to the plasticware in experiments without FBS, tissue culture dishes were precoated with $20 \mu \mathrm{g} / \mathrm{mL}$ bovine serum albumin (Sigma, Cat\# A1470) and rinsed with serum-free medium before 


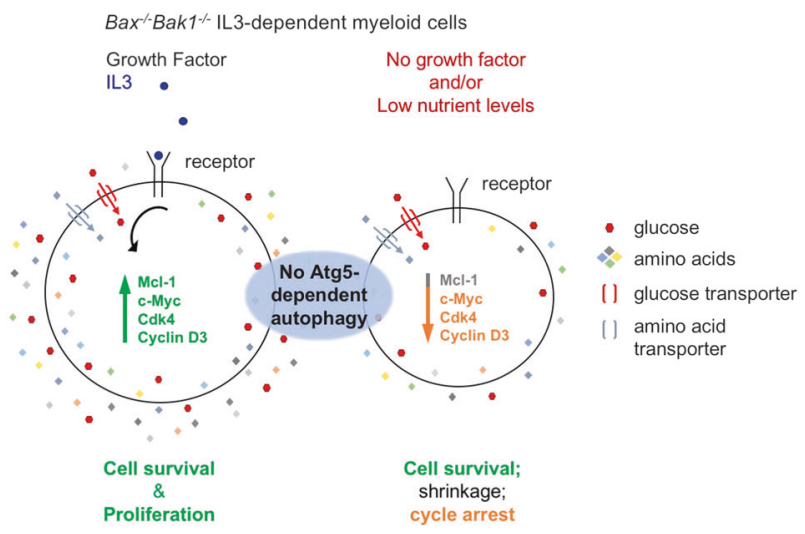

Fig. 8 The growth factor IL-3 stimulates the expression of Mcl-1 that inhibits activation of Bax/Bak1, and stimulates expression of c-Myc, Cdk4 and cyclin D3 to promote cell growth and division. Optimal concentrations of glucose and glutamine are required to maintain levels of these proteins needed to prevent activation of Bax/Bak1 (Mcl-1), as well as for cell proliferation (c-Myc, Cdk4, cyclin D3 and possibly others). In the absence of growth factor, or when nutrient levels are low, sufficient levels of glucose transporters (Glut1, Glut4 and possibly others) remain to allow $\mathrm{Bax}^{-/-} \mathrm{Bakl}^{-/-}$myeloid cells to consume extracellular glucose to survive, even in cells lacking Atg5dependent autophagy

cell seeding. DMEM lacking D-glucose but containing $4 \mathrm{mM}$ L-glutamine (Cat\# 11966-025) and DMEM lacking both Dglucose and L-glutamine (Cat\# A14430-01) were purchased from Thermo Fisher Scientific. D-Glucose was purchased from Sigma (Cat\# G7528). The glucose concentration in FBS was determined using an Accu-Chek Performa glucose meter, according to the manufacturer's instructions.

\section{Lentiviral constructs for CRISPR/Cas9 and inducible overexpression}

An inducible lentiviral CRISPR/Cas9 system [20] was used to mutate Txnip in $\mathrm{Bax}^{-1-} \mathrm{Bakl}^{-1-}$ FDM cells. Guide RNA oligos targeting mouse Txnip (guide 1: CCA GCA GGT GAG AAC GAG A; guide 2: TAT GGT TGC GTA GAC TAC T) were cloned into the BsmBI site of the pFgH1tUTG GFP lentiviral vector. Guide RNA oligo targeting mouse Atg5 (AAG ATG TGC TTC GAG ATG TG) was cloned into the BsmBI site of the lentiviral vector lentiCRISPR v2 (Addgene, \#52961 [21]). For overexpression studies, the coding sequence of mouse Txnip was PCR amplified from pEGFP-C1-Txnip (Addgene, \#18758 [22]) with the incorporation of an N-terminal FLAG tag. The PCR product was cloned into the EcoRI/NheI sites of a doxycycline-inducible pFTREtight MCS rtTAadvanced GFP lentiviral vector [23].

\section{Antibodies and small molecules}

Antibodies: LC3B (D11, Cell Signaling Technology, \#3868), Atg5 (D5F5U, Cell Signaling Technology,
\#12994); $\beta$-actin (AC-15, Sigma, \#A1978), Glut1 (Abcam, ab15730), Txnip (D5F3E, Cell Signaling Technology, \#14715 S), Glut4 (1F8, Cell Signaling Technology, \#2213), Mcl-1 (Rockland, 600-401-394S), c-Myc (Abcam, ab32072), Cdk4 (Santa Cruz Biotechnology, sc-260), Cyclin D3 (Cell Signaling Technology, \#2936), and Atf4 (D4B8, Cell Signaling Technology, \#11815). Small molecules: Mcl-1 inhibitor S63845 was synthesized according to Kotschy et al. [12] by SYNthesis Med Chem Pty Ltd (Parkville, Australia) or by Active Biochem (Catalog\# A-6044-a kind gift from David Huang); dimethyl sulfoxide (Cat\# 472301) and propidium iodide (Cat\# P4864) were purchased from Sigma.

\section{Measurements of cell death, cell cycle, and cell size}

Cell death and cell cycle were assayed using propidium iodide (PI) and flow cytometry. For death assays, cells were harvested and resuspended in phosphate-buffered saline (PBS) containing $1 \mu \mathrm{g} / \mathrm{mL}$ PI. For cell cycle analysis, cells were harvested and resuspended in PBS containing 0.1\% Triton X-100, $5 \mu \mathrm{g} / \mathrm{mL}$ PI, and $10 \mu \mathrm{g} / \mathrm{mL}$ RNaseA (Thermo Scientific), and then incubated at $37^{\circ} \mathrm{C}$ for $15 \mathrm{~min}$. Samples were processed on FACSCalibur or LSRFortessa X-20 flow cytometers (BD Biosciences) and the acquired data analyzed with the FlowJo software. Cell volume in Fig. 5 was measured using a CASY Coulter-based cell counter (Roche Innovatis AG). In brief, $200 \mu \mathrm{L}$ aliquots of cells cultured under the specified conditions were mixed with $5 \mathrm{~mL}$ of CASY electrolyte buffer and analyzed in a $60 \mu \mathrm{m}$ CASY capillary. Multiple parameters including the peak cell volume were collected.

\section{Glucose uptake assays}

ECAR rates were measured in live cells using a Seahorse Bioscience XFe96 Analyzer (Agilent Technologies). In brief, cells were resuspended in non-buffered DMEM (Seahorse Biosciences) and $200 \times 10^{3}$ cells were seeded per well in Seahorse Bioscience 96-well plates. The cellular ECAR was analyzed in non-buffered DMEM containing $2 \mathrm{mM}$ glutamine with the following compounds: $5 \mathrm{mM}$ glucose, $1 \mu \mathrm{M}$ oligomycin, and $50 \mathrm{mM}$ 2-deoxyglucose. For each assay cycle, measurement time points of $2 \mathrm{~min}$ mix, $2 \mathrm{~min}$ wait, and $5 \mathrm{~min}$ measure were collected.

\section{Data reproducibility}

Unless indicated otherwise, all experiments shown have been reproduced at least three independent times with similar results. While not all repeats were performed wholly or in exact detail, we ensured that our experimental design allowed us to interpret and draw conclusions from multiple 
independent experiments. This is aided by the fact that our results are unambiguous: the majority of cells are either alive or dead, cycling or arrested, large or small, and immunoblots show clear changes in protein levels or modification. We have endeavored to perform experiments that provide consistent evidence in mechanistically independent ways, rather than repeating the same experiment many times until statistical significance is reached. The experimental triangulation of our evidence [24] is best exemplified by multiple independent assays confirming that autophagy-deficient FDM cells survived for weeks without growth factor under a variety of different culture conditions (Figs. 2b, 4b, 5, 7c and Supplementary Fig. S3B).

Acknowledgements We thank Gabriela Brumatti, Rebecca Feltham, James Vince, Simon Monard, David Huang, and Andre Samson for discussion, technical advice, and reagents. Funding for this project was provided by the Australian National Health and Medical Research Council (NHMRC) Program Grant \#1113133 and NHMRC fellowship 1020136 to DLV; and the Leukemia and Lymphoma Society SCOR grant \#7001-13. Work in the authors' laboratory is made possible by operational infrastructure grants through the Australian Government Independent Research Institutes Infrastructure Support (IRISS) and the Victorian State Government OIS.

\section{Compliance with ethical standards}

Conflict of interest The authors declare that they have no conflict of interest.

Publisher's note: Springer Nature remains neutral with regard to jurisdictional claims in published maps and institutional affiliations.

\section{References}

1. Perkins AC, Cory S. Conditional immortalization of mouse myelomonocytic, megakaryocytic and mast cell progenitors by the Hox-2.4 homeobox gene. EMBO J. 1993;12:3835-46.

2. Ekert PG, Read SH, Silke J, Marsden VS, Kaufmann H, Hawkins CJ, et al. Apaf-1 and caspase-9 accelerate apoptosis, but do not determine whether factor-deprived or drug-treated cells die. J Cell Biol. 2004;165:835-42.

3. Vaux DL, Cory S, Adams JM. Bcl-2 gene promotes haemopoietic cell survival and cooperates with c-myc to immortalize pre-B cells. Nature. 1988;335:440-2.

4. Lum JJ, Bauer DE, Kong M, Harris MH, Li C, Lindsten T, et al. Growth factor regulation of autophagy and cell survival in the absence of apoptosis. Cell. 2005;120:237-48.

5. Mizushima N, Komatsu M. Autophagy: renovation of cells and tissues. Cell. 2011;147:728-41.https://doi.org/710.1016/j.cell.2011.1010.1026.

6. Roy S, Leidal AM, Ye J, Ronen SM, Debnath J. Autophagydependent shuttling of TBC1D5 controls plasma membrane translocation of GLUT1 and glucose uptake. Mol Cell. 2017;6:020.

7. Wu N, Zheng B, Shaywitz A, Dagon Y, Tower C, Bellinger G. et al. AMPK-dependent degradation of TXNIP upon energy stress leads to enhanced glucose uptake via GLUT1. Mol Cell. 2013;49:116775.https://doi.org/1110.1016/j.molcel.2013.1101.1035.

8. Dexter TM, Garland J, Scott D, Scolnick E, Metcalf D. Growth factor-dependent hemopoietic precursor cell lines. J Exp Med. 1980;152:1036-47.

9. Loos B, du Toit A, Hofmeyr JH. Defining and measuring autophagosome flux-concept and reality. Autophagy. 2014;10:2087-96.

10. Lindqvist LM, Heinlein M, Huang DC, Vaux DL. Prosurvival Bcl-2 family members affect autophagy only indirectly, by inhibiting Bax and Bak. Proc Natl Acad Sci USA. 2014;111:8512-7. https://doi.org/8510.1073/pnas.1406425111.

11. Le A, Lane AN, Hamaker M, Bose S, Gouw A, Barbi J. et al. Glucose-independent glutamine metabolism via TCA cycling for proliferation and survival in B cells. Cell Metab. 2012;15:110-21. https://doi.org/110.1016/j.cmet.2011.1012.1009.

12. Kotschy A, Szlavik Z, Murray J, Davidson J, Maragno AL, Le Toumelin-Braizat G, et al. The MCL1 inhibitor S63845 is tolerable and effective in diverse cancer models. Nature. 2016;538:477-82.

13. Dolezal E, Infantino S, Drepper F, Borsig T, Singh A, Wossning $\mathrm{T}$, et al. The BTG2-PRMT1 module limits pre-B cell expansion by regulating the CDK4-Cyclin-D3 complex. Nat Immunol. 2017;18:911-20.

14. Sawai CM, Freund J, Oh P, Ndiaye-Lobry D, Bretz JC, Strikoudis A, et al. Therapeutic targeting of the cyclin D3:CDK4/6 complex in T cell leukemia. Cancer Cell. 2012;22:452-65.

15. Harding HP, Zhang Y, Zeng H, Novoa I, Lu PD, Calfon M, et al. An integrated stress response regulates amino acid metabolism and resistance to oxidative stress. Mol Cell. 2003;11:619-33.

16. Ekert PG, Jabbour AM, Manoharan A, Heraud JE, Yu J, Pakusch $\mathrm{M}$, et al. Cell death provoked by loss of interleukin-3 signaling is independent of Bad, Bim, and PI3 kinase, but depends in part on Puma. Blood. 2006;108:1461-8.

17. Ben-David U, Siranosian B, Ha G, Tang H, Oren Y, Hinohara K, et al. Genetic and transcriptional evolution alters cancer cell line drug response. Nature. 2018;560:325-30.

18. Hecht VC, Sullivan LB, Kimmerling RJ, Kim DH, Hosios AM, Stockslager MA, et al. Biophysical changes reduce energetic demand in growth factor-deprived lymphocytes. J Cell Biol. 2016;212:439-47.

19. B'Chir W, Maurin AC, Carraro V, Averous J, Jousse C, Muranishi $\mathrm{Y}$, et al. The eIF2alpha/ATF4 pathway is essential for stress-induced autophagy gene expression. Nucleic Acids Res. 2013;41:7683-99.

20. Aubrey BJ, Kelly GL, Kueh AJ, Brennan MS, O'Connor L, Milla $\mathrm{L}$, et al. An inducible lentiviral guide RNA platform enables the identification of tumor-essential genes and tumor-promoting mutations in vivo. Cell Rep. 2015;10:1422-32.

21. Sanjana NE, Shalem O, Zhang F. Improved vectors and genomewide libraries for CRISPR screening. Nat Methods. 2014;11: $783-4$.

22. Wang Z, Rong YP, Malone MH, Davis MC, Zhong F, Distelhorst $\mathrm{CW}$. Thioredoxin-interacting protein (txnip) is a glucocorticoidregulated primary response gene involved in mediating glucocorticoid-induced apoptosis. Oncogene. 2006;25:1903-13.

23. Brumatti G, Salmanidis M, Kok CH, Bilardi RA, Sandow JJ, Silke $\mathrm{N}$, et al. HoxA9 regulated Bcl-2 expression mediates survival of myeloid progenitors and the severity of HoxA9-dependent leukemia. Oncotarget. 2013;4:1933-47.

24. Munafo MR, Davey Smith G. Robust research needs many lines of evidence. Nature. 2018;553:399-401. 